\title{
Experimental Study on Influence of Borehole Arrangement on Energy Conversion and Acoustic Characteristics of Coal-Like Material Sample
}

\author{
Chuanbo Hao, ${ }^{1}$ Zhiyuan Hou $\mathbb{D}^{2}{ }^{2}$ Fukun Xiao, ${ }^{3}$ and Gang Liu ${ }^{3}$ \\ ${ }^{1}$ Heilongjiang University of Science and Technology, Harbin 150022, China \\ ${ }^{2}$ School of Safety Engineering, Heilongjiang University of Science and Technology, Harbin 150022, China \\ ${ }^{3}$ Heilongjiang Ground Pressure \& Gas Control in Deep Mining Key Lab, Heilongjiang University of Science and Technology, \\ Harbin 150022, China \\ Correspondence should be addressed to Zhiyuan Hou; houzhiyuan0814@126.com
}

Received 14 September 2019; Revised 14 August 2020; Accepted 27 August 2020; Published 8 September 2020

Academic Editor: Jean-Jacques Sinou

Copyright (C) 2020 Chuanbo Hao et al. This is an open access article distributed under the Creative Commons Attribution License, which permits unrestricted use, distribution, and reproduction in any medium, provided the original work is properly cited.

\begin{abstract}
This paper examines the effects of borehole arrangement on the failure process of coal-like materials based on its energy conversion and acoustic characteristics from the perspectives of energy, AE energy, AE spectrum, and frequency band. Findings from the study revealed that the presence of borehole can significantly reduce the conversion ratio and growth rate of elastic energy during the loading of coal-like material sample and delay the release of internal energy of the sample. Also, it can reduce the frequency band energy of the main frequency of acoustic emission signal but has little effect on the size and richness of the peak frequency of acoustic emission signal. The practice that makes drilling diameter and depth increase stepwise can minimize the elastic energy conversion ratio, the growth rate, and the main frequency band energy of acoustic emission signal of coal-like material sample and postpone the internal energy release of the sample to the greatest extent, so as to enrich the richness of the secondary frequency of acoustic emission signal. The results of this study have certain guiding significance for the layout of pressure relief boreholes in the production process of coal mines.
\end{abstract}

\section{Introduction}

Increment in mining depths results in an increase in the crustal stress of the coal body, making the occurrence of rock burst a restricting factor in the safe and efficient production of coal in China $[1,2]$. At present, common control methods of rock burst are borehole pressure relief, coal steam water injection, and roof loose blasting. The method of borehole pressure relief is the most convenient and widely used. The common pressure relief method is mainly large-diameter borehole pressure relief [3-5].

In recent years, domestic and foreign scholars have used numerical simulation, laboratory tests, and field tests to study the mechanism and form of pressure relief borehole. Wen et al. [6-8] used numerical simulation to simulate the process of pressure relief drilling in roadway and combined it with elastoplastic theory to discuss the changes in stress and strain field around the borehole. From numerical calculation, the mechanical mechanism of borehole pressure relief was revealed, and the effect of pressure-relief borehole on the change in stress field of coal and rock mass was analyzed. The process of rock burst is an instantaneous release of energy. Energy changes in coal and rock masses need to be further analyzed. Li et al. [9-11] used numerical simulation to optimize the parameters of pressure-relief boreholes and discussed the effects of changes in borehole diameter and depth on pressure relief. The situation in which the diameter changes with depth was not analyzed. Huang et al. [12-14] optimized the pressure-relief borehole parameters from the perspectives of mechanical parameters, AE counts, crack development, and energy dissipation using the method of laboratory test. The research results showed 
that the diameter, spacing, and number of pressure-relief bore holes have significant effects on the strength and fracture morphology of the sample. However, the above research results did not explore the mutual conversion between the internal elastic energy, the dissipative energy, and the evolution of acoustic emission characteristics. $\mathrm{Hu}$ et al. [15-18] carried out loading tests on hard rocks with boreholes, combined with the fracture form, energy dissipation, and acoustic emission characteristic parameters to analyze the rock burst process of hard rocks, and analyzed the effect of stress changes and water content around the borehole on hard rock bursts during the rock burst process. Only a single-hole experimental study was conducted in the above study. The hard rock characteristics under the influence of porous combinations need to be further explored. Liu et al. [19] used a large number of experiments to establish the functional relationship between borehole diameter, coal seam thickness, gain coefficient, and safety increment and applied it to coal mining face to determine a reasonable borehole diameter and borehole spacing. However, the determination of the drilling depth requires further study. Konicek et al. [4] used the Seismic Effect (SE) and Compact Conical-ended Borehole Monitoring (CCBM) method to optimize the deep borehole pressure relief technology for the No. 504 coal seam in the Ostrava-Karvina coalfield. The previously mentioned scholars have carried out theoretical research, numerical calculations, and laboratory experiments mainly on the mechanism and parameter optimization of pressure relief drilling, but there are few experiments on the combination process of pressure relief borehole from the perspective of energy conversion process and acoustic emission characteristics. For this reason, from the perspective of the energy accumulation and dissipation in coal mine rock burst, this paper discusses the effect of pressure relief drilling on energy conversion and dissipation of coal-like materials and the effect of drilling arrangement on pressure relief effect. The results have certain guiding significance for the layout of pressure relief drilling in coal mines.

To achieve the stated aim, this paper carried out mechanical tests on coal-like materials with prefabricated holes and used the acoustic emission monitoring system to monitor the whole process. Based on the first law of thermodynamics, from the perspectives of energy conversion, AE energy, AE frequency spectrum, and $\mathrm{AE}$ frequency band energy, the effects of drilling arrangement on the energy conversion and acoustic characteristics of coal-like materials are discussed and analyzed.

\section{Test Scheme and Condition}

2.1. Sample Preparation. Due to the various steps (chipping, transportation, and cutting) involved in the preparation of the coal samples, it is inevitable that secondary damage to the coal sample would occur during the production process, which can further expand the joints and cracks inside the coal sample; it is therefore difficult to quantitatively analyze coal samples in different borehole arrangements. This paper uses orthogonal test design to prepare similar materials for the coal samples (mechanical properties). In this paper, $L_{16}\left(4^{4}\right)$ orthogonal test design is selected, and regression analysis is performed on the test results to determine the cement:gypsum:sand: pulverized coal : water ratio of coal-like materials, which is 6 : $2: 1: 3: 5.04$. The acoustic emission and mechanical properties of coal-like materials and raw coal are, respectively, illustrated in Figure 1 and Table 1. Figure 1 and Table 1 show that the mechanical properties of similar materials and raw coal samples are highly similar under this proportion, not only in terms of mechanical parameters but also in the change of stress-strain curve. There are obvious compaction stages, elastic deformation stages, plastic deformation stages, and strain softening stage. At the same time, it can be seen from the distribution of AE signals that a large number of fracture acoustic signals are generated before the failure of similar materials, which is also highly similar to raw coal. Therefore, it is feasible to use this similar material to replace raw coal. According to the above ratio requirements, a standard sample of $100 \mathrm{~mm} \times 100 \mathrm{~mm} \times 100 \mathrm{~mm}$ was prepared. The test was divided into five groups, which are scheme I, complete samples; scheme II, samples with boreholes (the borehole diameters are $8 \mathrm{~mm}$ and the borehole depths are $50 \mathrm{~mm}$ ); scheme III, samples with borehole with stepwise increased borehole depth (boreholes diameter is $8 \mathrm{~mm}$, drilling depth is $50 \mathrm{~mm}, 60 \mathrm{~mm}$, and $70 \mathrm{~mm}$ in turn); scheme IV, samples with borehole with stepwise increased borehole diameter (drilling diameter is $6 \mathrm{~mm}, 8 \mathrm{~mm}$, and $10 \mathrm{~mm}$; borehole depth is $50 \mathrm{~mm}$ ); and scheme V, samples with borehole with stepwise increased borehole depth and borehole diameter (the diameter of the drilling is $6 \mathrm{~mm}, 8 \mathrm{~mm}$, and $10 \mathrm{~mm}$, and the drilling depth is $50 \mathrm{~mm}, 60 \mathrm{~mm}$, and $70 \mathrm{~mm}$ ), as shown in Figure 2.

\subsection{ExperimentalEquipment and Parameter Setting. The test} loading equipment was TYJ-500 kN electrohydraulic servo rock mechanics testing machine. This test system can monitor the stress and strain during the loading process of coal-like material samples. The pressure control range was $0 \sim 500 \mathrm{kN}$, and the stress monitoring accuracy was $0.001 \mathrm{kN}$. The monitoring precision of extensometer was $0.001 \mathrm{~mm}$. Displacement loading was carried out with a loading speed of $0.05 \mathrm{~mm} / \mathrm{s}$ in test process. The test monitoring system used SH-II type acoustic emission monitoring system produced by American Physical Acoustics Company. The acoustic emission monitoring system used Nano30 sensors arranged on the left and right sides of the sample. Static calibration tests were conducted in the laboratory before the test. The test found that when the threshold is set to $40 \mathrm{~dB}$, mechanical noise such as external collision and friction can be effectively eliminated; during the experiment, the sampling frequency was $750 \mathrm{kHz}$ and the signal amplification factor is 100 times. In order to prevent friction between the press and the sample causing errors in the acoustic emission monitoring system during the test, the Vaseline coupling agent should be applied to the two sections in contact with the press. The test system is illustrated in Figure 3. 


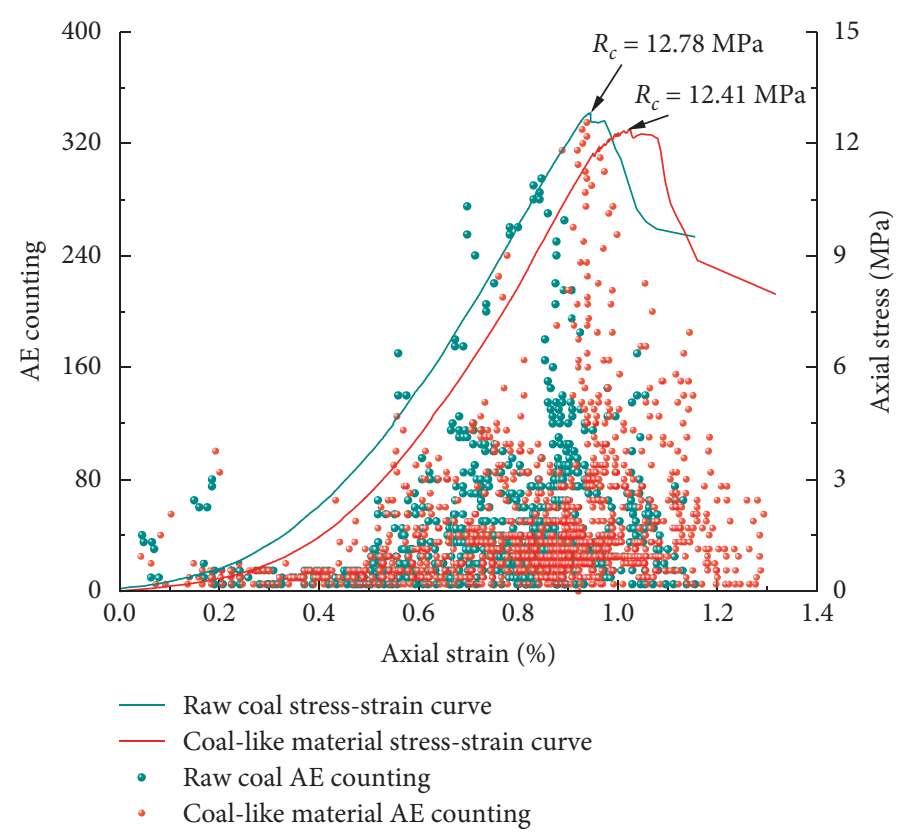

(a)

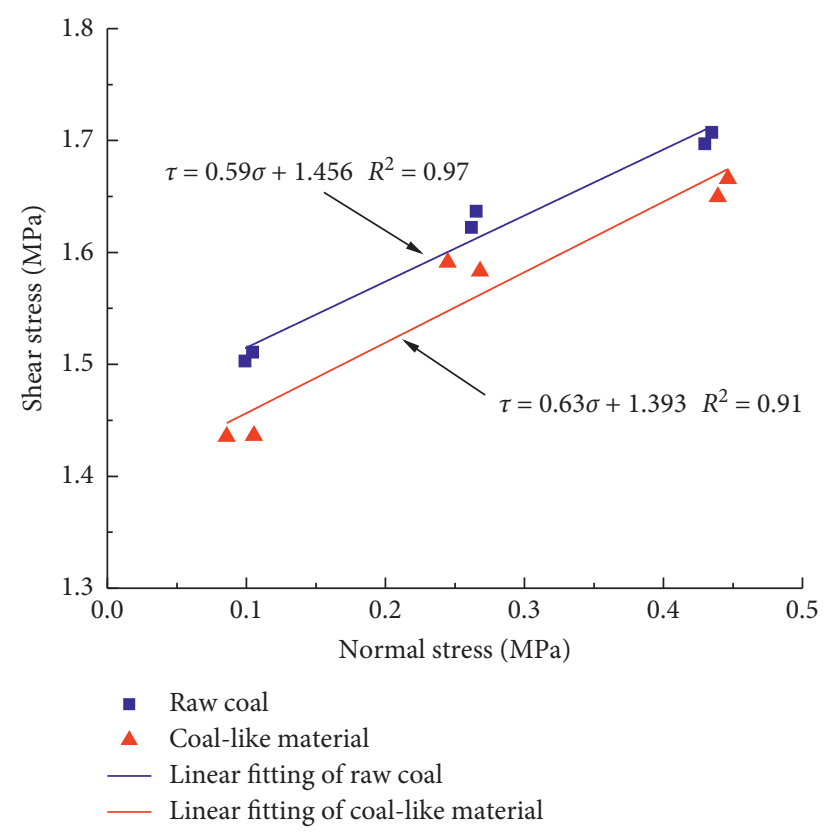

(b)

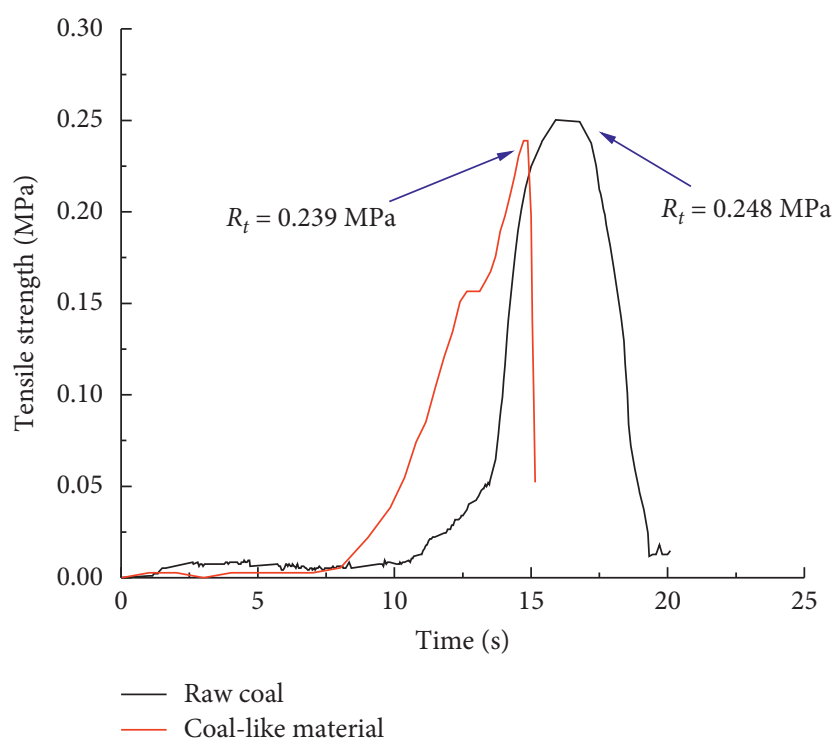

(c)

Figure 1: Mechanical and acoustic emission properties of coal-like material. (a) Typical curves of uniaxial stress strain. (b) Typical curves of variable-angle shear strength and AE counting. (c) Typical curves of tensile strength.

TABLE 1: Comparison of mechanical properties between raw coal and coal-like material.

\begin{tabular}{lccccrr}
\hline Category & $R_{\mathrm{c}}(\mathrm{MPa})$ & $E(\mathrm{GPa})$ & $\mu$ & $C(\mathrm{MPa})$ & $\varphi\left(^{\circ}\right)$ & $R_{\mathrm{t}}(\mathrm{MPa})$ \\
\hline Raw coal & 12.23 & 1.62 & 0.20 & 1.44 & 31.09 & 0.252 \\
Coal-like material & 12.06 & 1.59 & 0.18 & 1.46 & 32.17 & 0.234 \\
\hline
\end{tabular}

Note: data are average values; curve is a typical curve. 


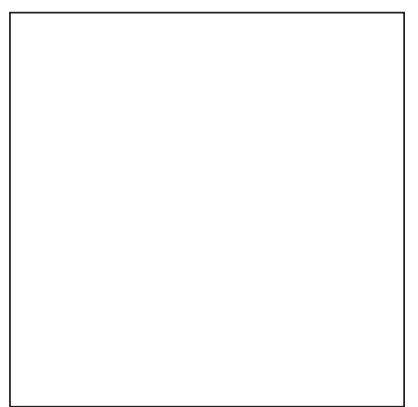

(a)

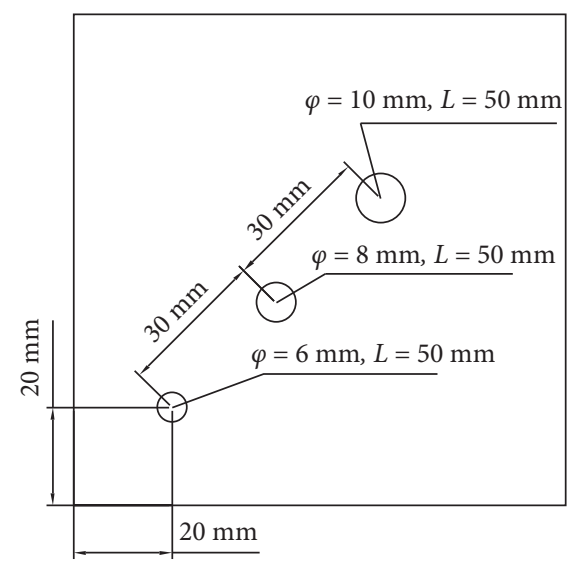

(d)

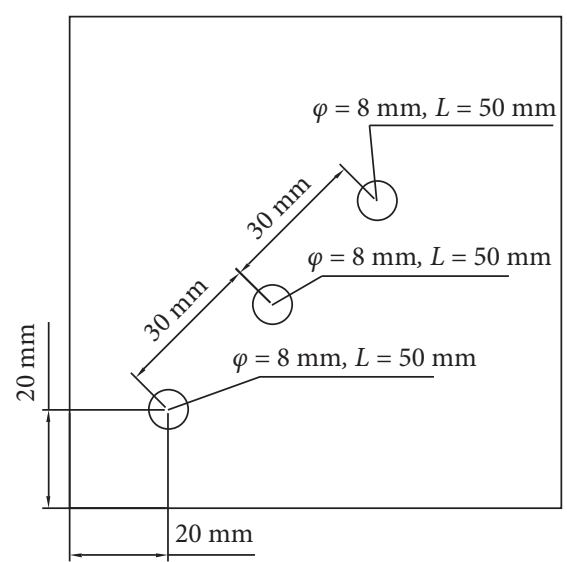

(b)

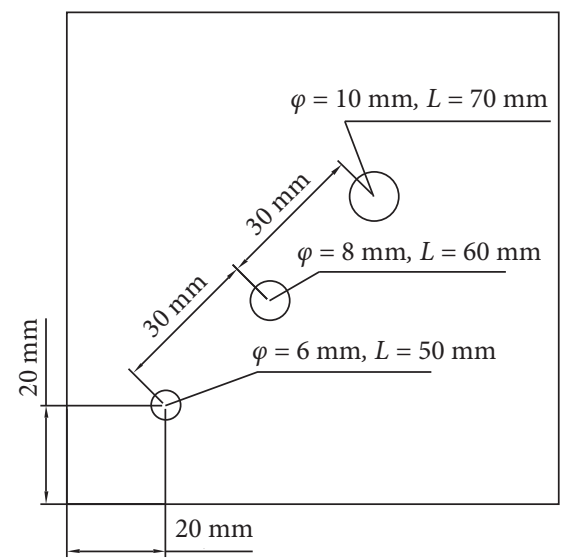

(e)

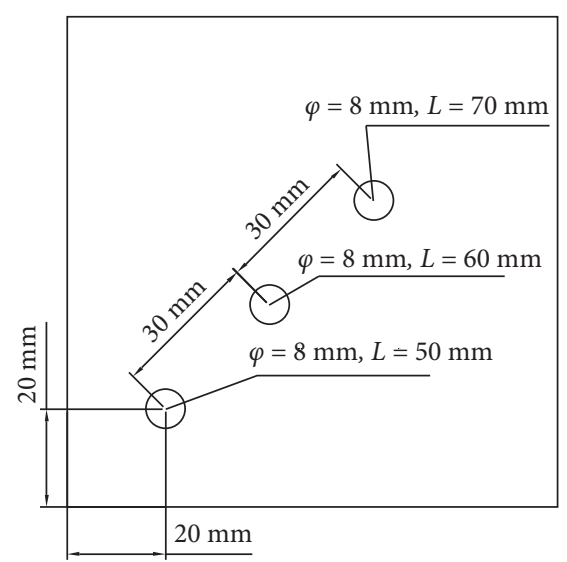

(c)

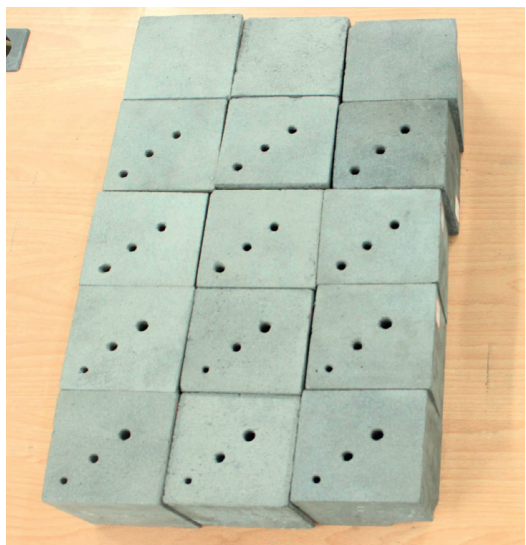

(f)

FIGURE 2: Sample layout of the borehole arrangement. (a) Scheme I: complete samples. (b) Scheme II: samples with boreholes. (c) Scheme III: samples with borehole with stepwise increased borehole depth. (d) Scheme IV: samples with borehole with stepwise increased borehole diameter. (e) Scheme V: samples with borehole with stepwise increased borehole depth and borehole diameter. (f) Part of the samples.

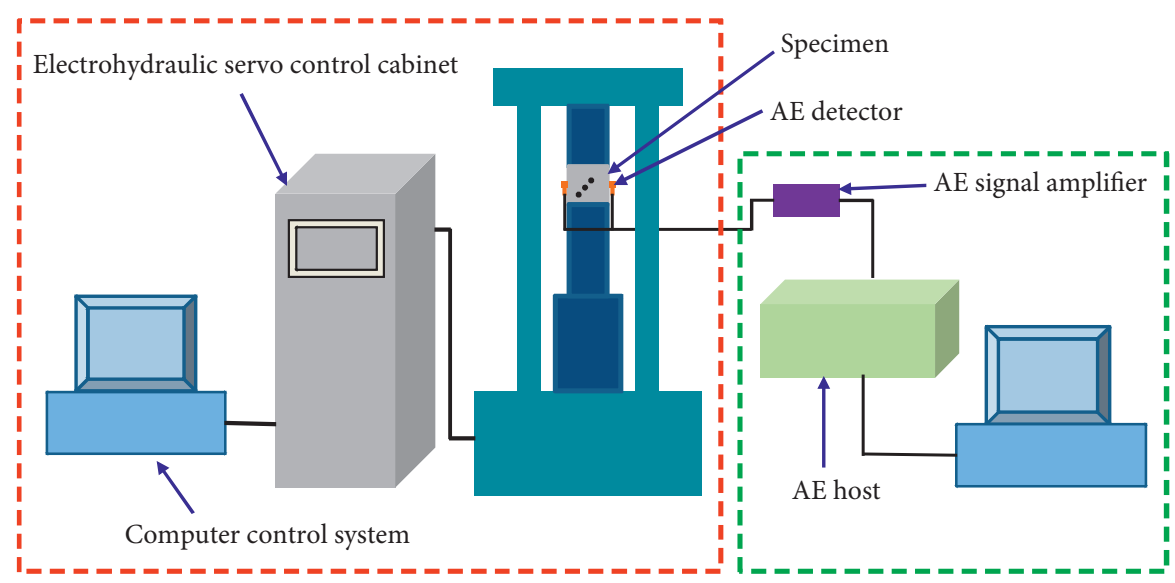

Figure 3: Test system. 


\section{Analysis of Influence of Borehole Arrangement on Coal-like Material Sample Energy Conversion}

3.1. Energy Calculation Method. During the experiment, the press continuously inputs energy into the sample, and the energy is converted into elastic strain energy and dissipated energy. The elastic deformation energy can be mainly stored in the sample and released with the unloading of the pressure. The energy dissipation mainly reflects the expansion and transformation of the crack in the sample into plastic deformation energy. This part of the energy is consumed during the loading process. Dissipative energy is irreversible with the unloading of pressure. It is assumed that there is no energy exchange between the test system and the environment, hence a closed system. According to the first law of thermodynamics, the total energy input by the press, the elastic strain energy accumulated by the coal-like material sample, and the dissipative energy satisfy the following relationship [20]:

$$
W=W_{s}+W_{d},
$$

where $W$ is the total energy input by the press, and its unit is $\mathrm{kJ} / \mathrm{m}^{3} ; W_{s}$ is the elastic deformation energy accumulated in the sample, and the unit is $\mathrm{kJ} / \mathrm{m}^{3} ; W_{d}$ is the dissipative energy in loading process, and the unit is $\mathrm{kJ} /$ $\mathrm{m}^{3}$.

The total energy input during the uniaxial loading of the coal-like material sample can be calculated based on the area enclosed by the stress-strain curve, and the elastic strain energy can be calculated according to the area enclosed by the unloading stress-strain curve. The specific relationship between the two energies is shown in Figure 4 [20].

The curve in the figure is the loading stress-strain curve of the coal-like material sample. $W_{s}^{i}$ is the elastic strain energy accumulated during the loading process, since the experiment is uniaxial loading, $\sigma_{2}$ and $\sigma_{3}$ are equal to 0 , and the calculation method of elastic strain energy is shown in formula (2) [20]. The physical meaning of elastic strain energy is the triangle area surrounded by unloading stress-strain curve in uniaxial loading. ${ }^{-} E$ is the average value of the elastic modulus $E_{\mathrm{d}}$ of the unloading curve; it can be replaced by the initial elastic modulus $E$ [20-23], so the calculation method of elastic strain energy is shown in formula (3) [24]. The input total energy $W$ is the work done by the press, which is calculated as formula (4), and its physical meaning is the area enclosed by the loading stress-strain curve. $W_{i}^{d}$ is the dissipative energy during the loading process of the curve, and the dissipative energy is irreversible during the unloading process of the sample. The calculation method is the difference between the inputted total energy and the stored elastic strain energy during the whole loading process, as shown in formula (5):

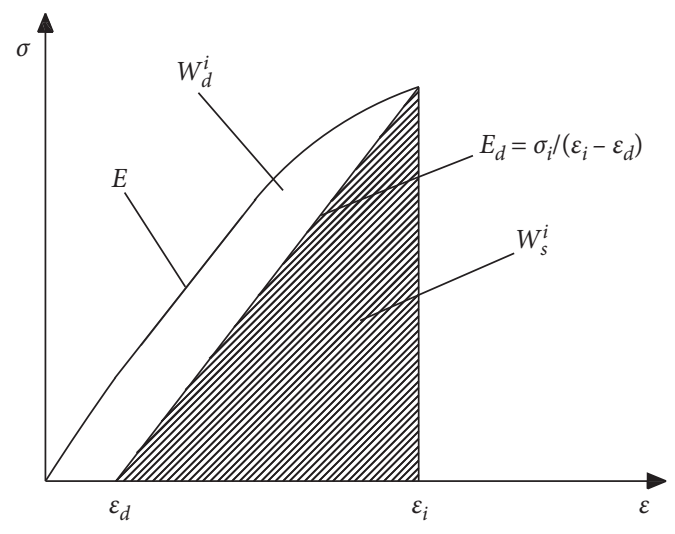

FIGURE 4: Relationship between elastic strain energy and dissipative energy in the coal and the rock units.

$$
W_{s}=\frac{1}{2 \bar{E}}\left[\sigma_{1}^{2}+\sigma_{2}^{2}+\sigma_{3}^{2}-2 \bar{v}\left(\sigma_{1} \sigma_{2}+\sigma_{2} \sigma_{3}+\sigma_{1} \sigma_{3}\right)\right]=\frac{1}{2 \bar{E}} \sigma_{1}^{2},
$$

$W_{s}=\frac{\sigma_{i}^{2}}{2 \bar{E}} \approx \frac{\sigma_{i}^{2}}{2 E}$

$$
W=\int \sigma d \varepsilon=\sum_{i=1}^{n-1} \int_{\varepsilon_{i}}^{\varepsilon_{i+1}} \sigma_{i} d \varepsilon=\sum_{i=1}^{n-1} \frac{\varepsilon_{i+1}-\varepsilon_{i}}{2}\left(\sigma_{i+1}+\sigma_{i}\right)
$$

$W_{d}=W-W_{s}$,

where $\varepsilon_{i}$ is the strain of sample when the stress is at $\sigma_{i}$ and $\varepsilon_{d}$ is the strain that cannot be recovered after the stress is unloaded from $\sigma_{i}$ to zero; ${ }^{-} E$ is the average elastic modulus of unloading curve; $E$ is the elastic modulus of the loading curve; ${ }^{-} v$ is the average Poisson's ratio of unloading curve; $\sigma_{1}, \sigma_{2}$, and $\sigma_{3}$ are the first principal stress, the second principal stress, and the third principal stress, respectively.

During the process of loading the coal-like material to the peak point, increment in the input energy results in an increase in the elastic strain energy stored. The speed of elastic strain energy growth is also an important factor in the stability control of coal-like material sample. To study the speed at which the elastic strain energy increases in the coallike material sample, we introduce a new variable, the elastic strain energy growth rate $W_{s}^{\prime}$, which is calculated as [25]

$$
W_{s}^{\prime}=\frac{d W_{s}}{d t} \text {. }
$$

3.2. Analysis of the Characteristics of Coal-like Material Sample Energy Conversion by Borehole Arrangement. Based on the principles and formulae discussed in (2) (6), the total energy $W$, elastic strain energy $W_{s}$, dissipative 
energy $W_{\mathrm{d}}$, and elastic strain energy growth rate $W_{\mathrm{s}}$ ' of the internal input of the coal-like material sample were calculated, respectively. The curves of the stress, the energy, and elastic energy growth rate with time were drawn, and the conversion process of internal energy during the process of loading coal-like material sample to the peak point was analyzed from the perspective of time domain, as shown in Figure 5.

Figure 5 showed that as the load of coal-like material sample increases, the total energy, elastic energy, and dissipated energy inside the sample increase, and the degree of elastic energy and dissipated energy conversion in different stages also differs. There is a definite relationship between the internal damage failure and the conversion between energies. Moreover, in the process of energy conversion, before the peak point of the load, the elastic energy inside the sample is always greater than the dissipative energy, indicating that the energy is mainly stored in the sample in the form of elastic strain energy before the coal-like material sample is loaded to the peak. According to the slope of the stress-strain curve during the loading of the sample, this curve can be divided into the initial compaction phase, the elastic deformation phase, and the plastic deformation phase. The concave part of the curve is the initial compaction phase. The straight part is the elastic deformation phase, and the convex part of the curve is the plastic deformation phase. The internal energy conversion of coal samples is analyzed from each stage of the loading process as follows:

(1) Compaction phase: in this phase, the elastic energy and dissipative energy of the initial compaction phase increase with an increase in total energy, and the overall trend shows a parabolic trend. The three curves have similar trends, and the growth rate of elastic energy tends to be gentle, indicating that, at this time, the internal pore gap compaction of the coal sample needs to consume a part of the energy, and the energy dissipated by this part also increases with an increase in the elastic energy. The dissipated energy of the complete sample (scheme I) in the compaction phase in Figure 5 is $1.91 \mathrm{~kJ} \cdot \mathrm{m}^{-3}$, and the dissipated energy in the compaction phase of the hole-containing test (scheme II) is $2.04 \mathrm{~kJ} \cdot \mathrm{m}^{-3}$. It can be seen that the existence of holes increases the dissipative energy in the compaction phase of the sample.

(2) Elastic phase: in this phase, the dissipation energy curve tends to be flat, but the total energy and elastic energy curve change trends are basically the same, the elastic energy curve shows a linear growth trend, and the elastic energy growth rate shows an upward trend, indicating that there is almost no energy dissipated at this stage. Almost all the energy input by the press is converted into elastic energy and stored in the coal sample. At this time, the internal microcracks of the coal sample develop steadily. The elastic energy accumulated in the elastic phase of the complete sample (scheme I) in Figure 5 is
$51.96 \mathrm{~kJ} \cdot \mathrm{m}^{-3}$, and the elastic energy accumulated in the elastic phase of the hole-containing test (Scheme II) is $41.46 \mathrm{~kJ} \cdot \mathrm{m}^{-3}$. The existence of holes significantly reduces the accumulation of the elastic energy of the sample.

(3) Plastic phase: in this phase, the dissipative energy curve becomes linear, while the elastic energy curve changes from linear growth to a parabola going downward with the elastic energy growth rate showing a downward trend. This shows that the total energy input at this stage is simultaneously converted into elastic energy and dissipated energy, but the elastic energy stored in the coal sample is slowed down, and the dissipated energy begins to increase. This part of the dissipative energy is mainly used for the unsteady and rapid expansion of the internal crack of the coal sample, and finally the coal sample bearing structure is destroyed. Among them, the dissipated energies of the complete sample and the sample with holes in the plastic deformation stage are, respectively, $12.73 \mathrm{~kJ} \cdot \mathrm{m}^{-3}$ and $23.50 \mathrm{~kJ} \cdot \mathrm{m}^{-3}$.

From the above analysis, the total energy input by the coal-like material sample is converted into elastic energy and dissipated energy, which are, respectively, stored in the sample and used for the expansion of the sample crack. It can be found that the conversion amount of elastic energy and dissipated energy in samples is different under different borehole arrangements. For this reason, by calculating the proportion of total elastic energy and dissipative energy conversion to total input energy under different drilling arrangements, the influence of different defect structures on energy conversion of coal-like material sample is analyzed. The results are presented in Table 2 .

From the conversion ratio of elastic energy and dissipative energy in Table 2, it can be seen that the defect structure has a significant influence on the energy conversion process. Comparing groups I and II in the whole sample I loading process, $83.19 \%$ of the total energy input by the press is converted into an elastic strain energy stored in the sample. The strength of the sample's unstable failure process is mainly caused by the internally accumulated elasticity. The more elastic energy accumulated, the greater the energy released during the failure. In Scheme II, the sample is subjected to structural defect. When loaded to the peak point, $73.19 \%$ of the total energy input is the elastic energy stored in the sample, and $26.81 \%$ of the energy is dissipated. Compared with Scheme I, Scheme II can significantly reduce the storage of elastic energy in the samples by structural defects, which can decrease the damage degree of the sample's instability. Comparing Scheme II and Scheme III, when increasing the depth of the defect borehole when the coal-like material sample is loaded to the peak intensity, the elastic energy conversion ratio in the sample is decreased by $8.11 \%$, and the defect drilling depth of Scheme III is increased compared with that of Scheme II. The elastic energy in the sample is reduced, thereby reducing the energy released when the sample is destroyed. In contrast to Schemes 


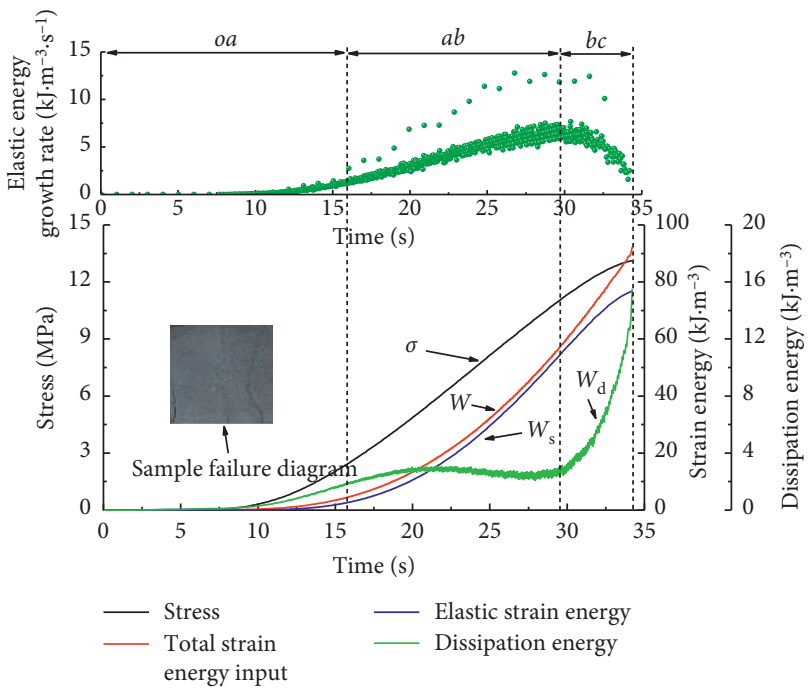

(a)

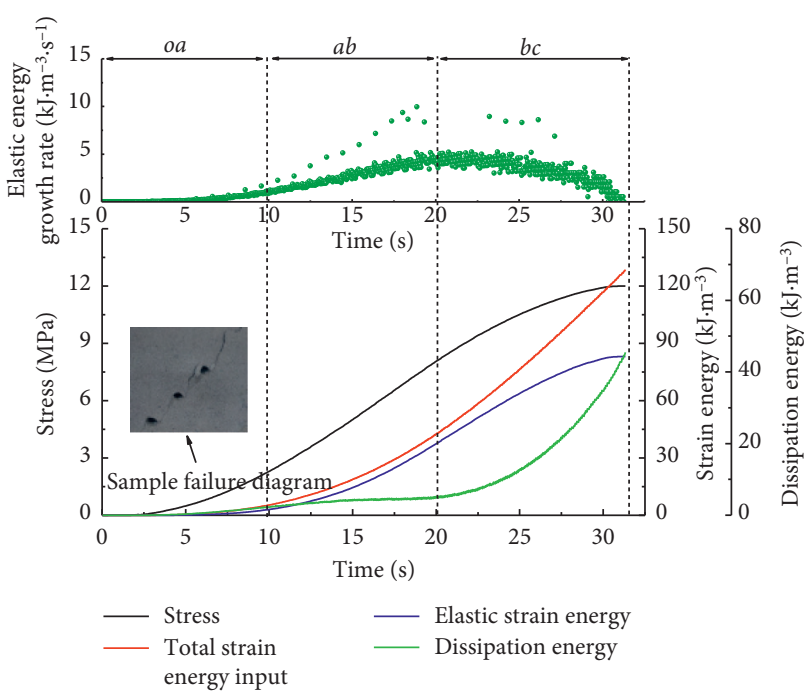

(c)

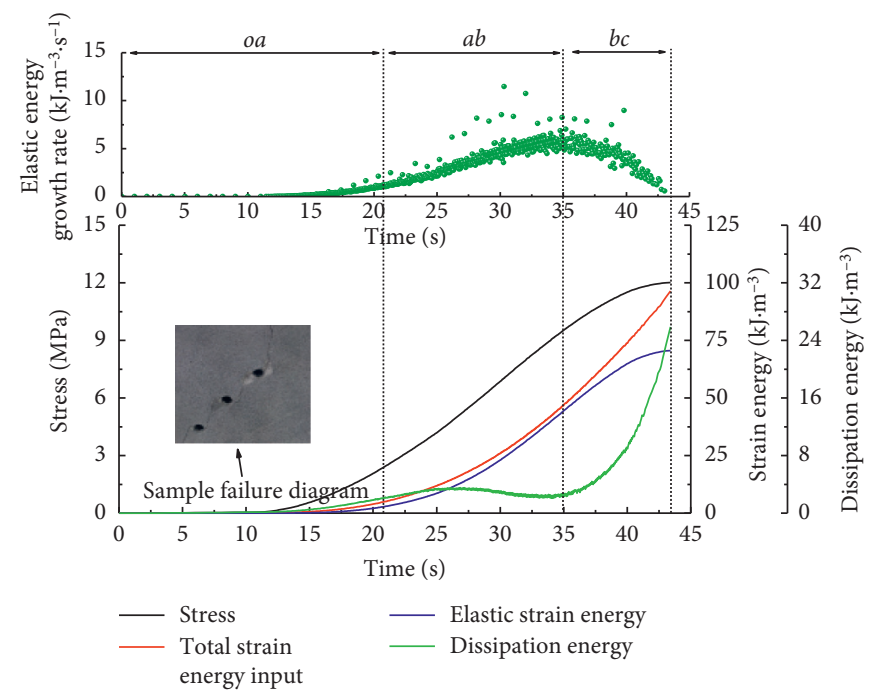

(b)

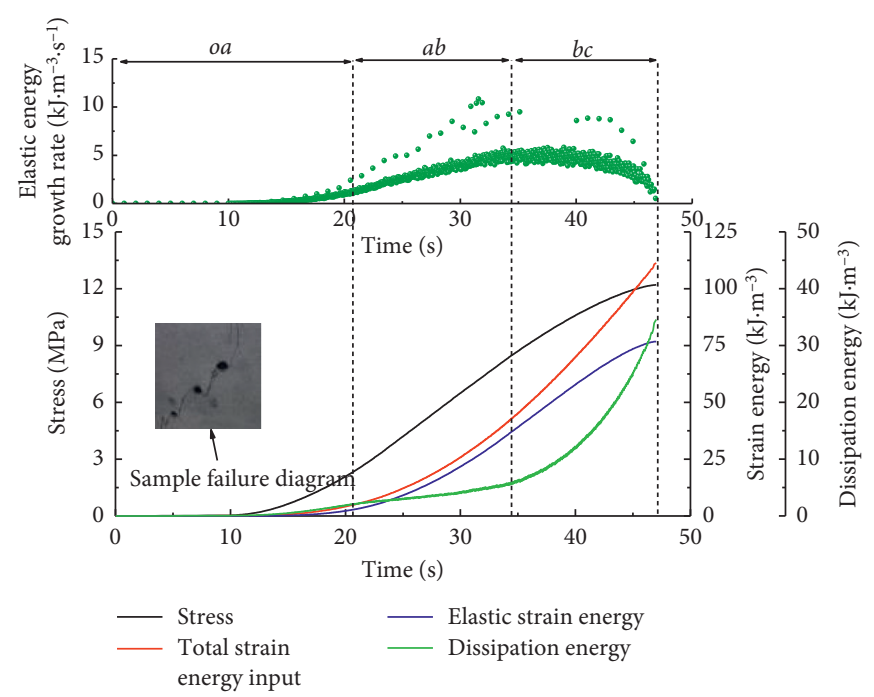

(d)

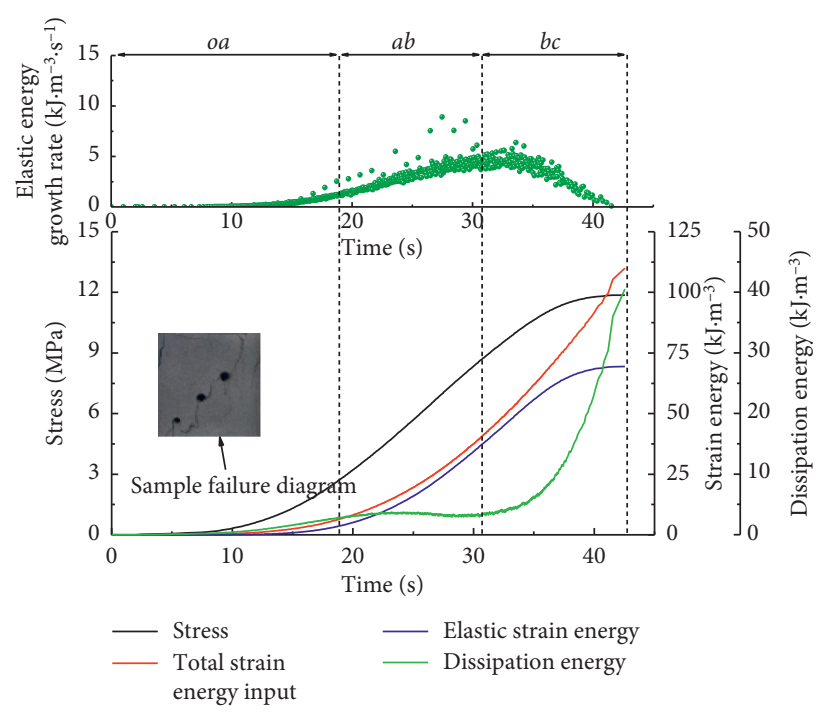

(e)

Figure 5: Typical curve of internal energy conversion and elastic energy growth rate of coal-like material sample under different borehole arrangements. (a) Scheme I 01: complete samples. (b) Scheme II 03: samples with boreholes. (c) Scheme III 02: samples with borehole with stepwise increased borehole depth. (d) Scheme IV 03: samples with borehole with stepwise increased borehole diameter. (e) Scheme V 01: samples with borehole with stepwise increased borehole depth and borehole diameter. 
TABLE 2: Internal energy conversion of coal-like material sample under different borehole arrangements.

\begin{tabular}{lcccccc}
\hline Group & Total energy $\left(\mathrm{kJ} \cdot \mathrm{m}^{-3}\right)$ & $\begin{array}{c}\text { Elastic energy } \\
\left(\mathrm{kJ} \cdot \mathrm{m}^{-3}\right)\end{array}$ & $\begin{array}{c}\text { Dissipated energy } \\
\left(\mathrm{kJ} \cdot \mathrm{m}^{-3}\right)\end{array}$ & $\begin{array}{c}\text { Elastic energy } \\
\text { conversion ratio }(\%)\end{array}$ & $\begin{array}{c}\text { Dissipated energy } \\
\text { conversion ratio }(\%)\end{array}$ & $\begin{array}{c}\text { Elastic energy growth rate } \\
\text { peak }\left(\mathrm{kJ} \cdot \mathrm{m}^{-3} \cdot \mathrm{s}^{-1}\right)\end{array}$ \\
\hline I & 92.275 & 76.752 & 15.523 & 83.18 & 16.82 & 12.75 \\
II & 96.469 & 70.603 & 25.865 & 73.19 & 26.81 & 11.49 \\
III & 127.699 & 83.105 & 44.594 & 65.08 & 34.92 & 9.96 \\
IV & 111.379 & 76.789 & 34.59 & 68.94 & 31.06 & 10.83 \\
V & 109.913 & 69.391 & 40.522 & 63.13 & 36.87 & 9.89 \\
\hline
\end{tabular}

II and IV, the pore diameter is changed and the coal-like material sample is loaded to the peak when the defect borehole depth is constant. At this point, the elastic energy of the internal storage decreased by $4.25 \%$, indicating that the change in borehole size has a certain influence on the transformation of the elastic energy in the sample, and Scheme V changes the diameter and depth of the defect borehole on the basis of the above scheme. The test results showed that when the two are combined, the storage of the coal-like material sample to the peak point stores the least amount of elastic energy, so the energy released when the sample is unstably destroyed is greatly reduced. At the same time, the growth rate of elastic energy during the loading of coal-like material samples is another important factor in judging the stability of the samples. The elastic energy conversion process and its speed are dynamic. The peak growth rate of energy can represent the maximum growth rate of the elastic energy. To this end, this paper studied the effect of structural defect on the internal energy conversion of coal from the perspective of the growth in elastic energy rate. Table 2 shows that the peak growth rate of the elastic energy during the whole coal loading process of Scheme I is $12.75 \mathrm{~kJ} \cdot \mathrm{m}^{-3} \cdot \mathrm{s}^{-1}$ (Scheme II), $9.96 \mathrm{~kJ} \cdot \mathrm{m}^{-3} \cdot \mathrm{s}^{-1}$ (Scheme III), $10.83 \mathrm{~kJ} \cdot \mathrm{m}^{-3} \cdot \mathrm{s}^{-1}$ (Scheme IV), $9.89 \mathrm{~kJ} \cdot \mathrm{m}^{-3} \cdot \mathrm{s}^{-1}$ (Scheme V), respectively. It can be seen that the arrangement of the defect structure reduces the peak growth rate of the elastic energy inside the coal, and increasing the diameter and the depth of the borehole can further reduce the conversion speed of the elastic energy. This indicates that the combination of the above two treatments can minimize the growth rate of elastic energy and can better maintain the stability of the coal-like material sample.

\section{Analysis of Influence of Borehole Arrangement on Acoustic Emission Characteristics of Coal-like Material Sample}

4.1. Analysis of Influence of Borehole Arrangement on Coal-like Sample AE Energy Release. Since the loading process of coal and rock mass is accompanied by the internal evolution, damage evolution will release energy outwards in the form of elastic wave. The AE energy is the area enclosed by the elastic wave envelope. The principle is shown in Figure 6. By analyzing the change in AE energy, it is possible to effectively evaluate the effect of the drilling arrangement on the internal energy release of the coal-like material samples.

Figure 7 shows the typical AE energy release during the loading of coal samples under different drilling

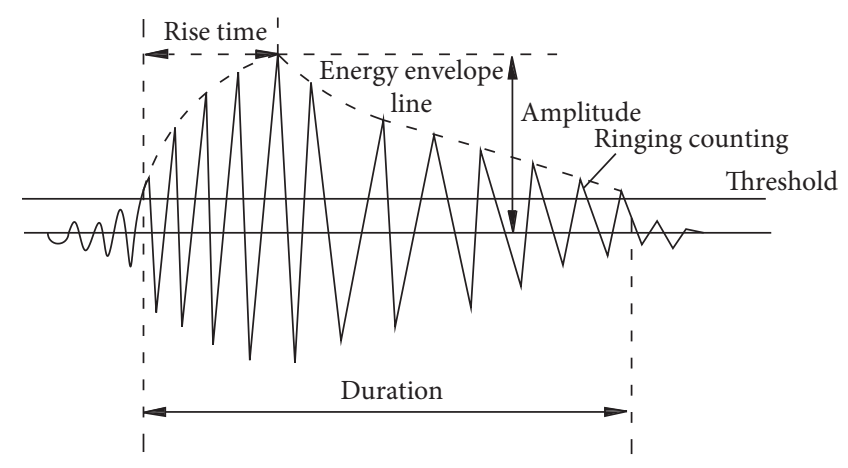

Figure 6: Principle of acoustic emission energy calculation.

arrangements. Due to the better homogeneity of the coal-like material, there are fewer internal secondary cracks compared with the coal sample. Acoustic emission monitoring results showed that the number of pulses is small. However, according to the distribution of the acoustic emission signal, the AE energy release inside the sample can be effectively reflected. It can be seen from the figure that the AE energy of the coal-like material sample varies obviously with the stress-time curve under different drilling arrangements, and the AE energy has obvious changes in each stage of the stress-time curve. By observing the AE energy jump point, it can be found that the peak load of the AE energy jump point of the complete sample (Scheme I) has a sudden increase before and after the peak load, and the energy of the AE jump point before the peak is significantly higher than that after the peak jump point; also, the AE jump point decreases overall. The trend indicates that there is an energy transient point inside the sample before and after the peak, and the instantaneous energy before the peak is greater than that after the peak. The AE energy jump point of the sample with boreholes occurs mostly after the peak load, and the overall energy value of the jump point after the peak load is higher than that before the peak load. At the same time, the arrangement of the borehole structure slows down the release of energy before the peak load of the coal-like material sample, and the increasing dissipated energy during the loading of the coal sample will be released into the free space of the borehole, reducing the degree of damage evolution of the sample. Schemes III, IV, and V are based on Scheme II in order to increase the diameter and the depth of the borehole simultaneously. By observing the AE energy release in the three schemes above, it can be found that after the diameter and the depth of the borehole were, respectively, increased, the AE energy release showed a lag trend on the basis of 

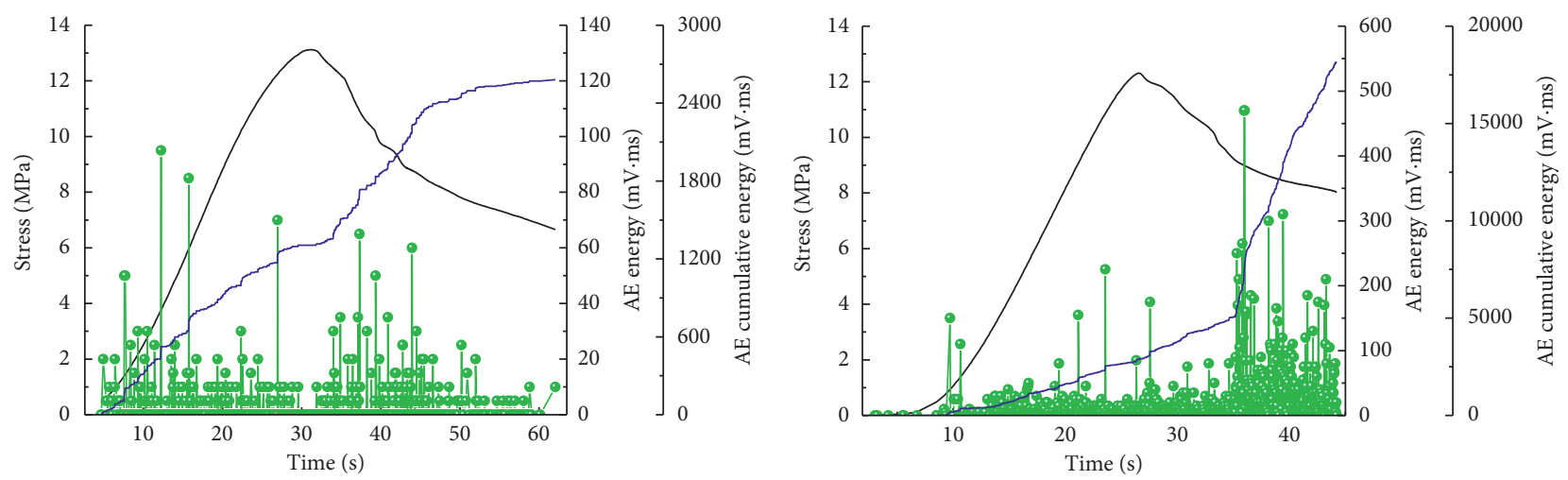

$$
\begin{aligned}
& \text { - Stress } \\
& \text { - AE cumulative energy } \\
& -\infty \text { AE energy }
\end{aligned}
$$

- Stress

- AE cumulative energy

- - AE energy

(a)

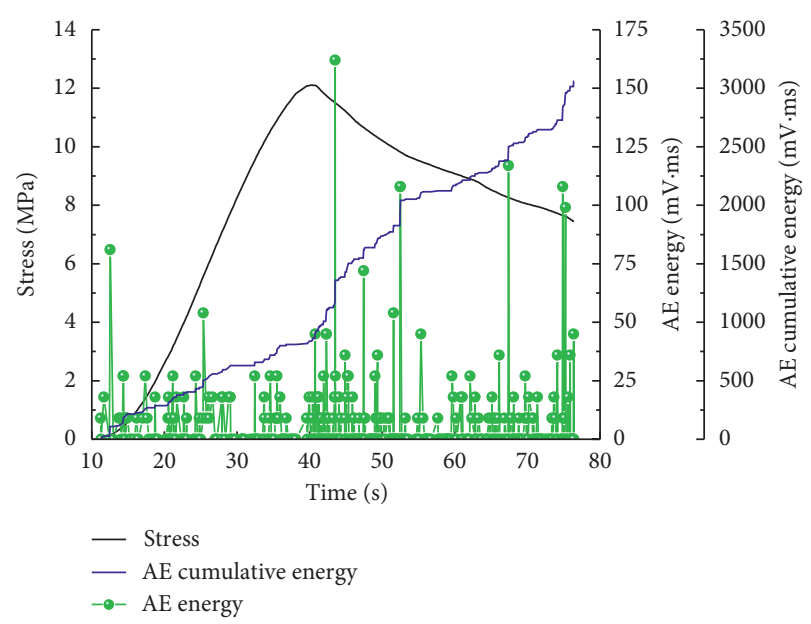

(c)

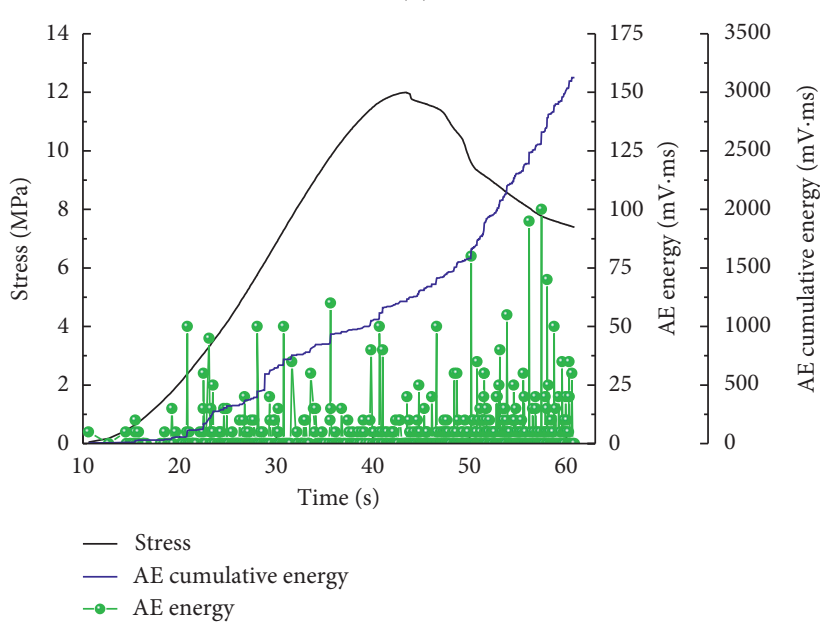

(d)

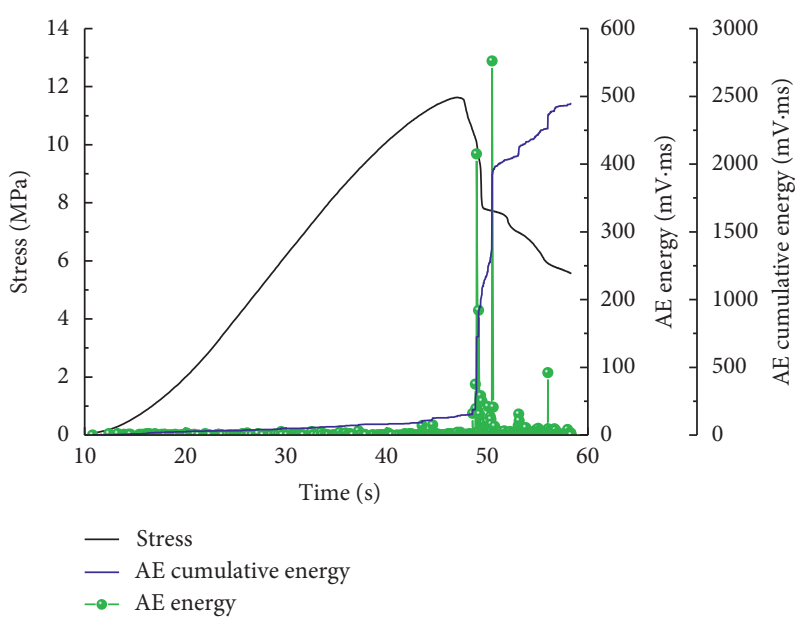

(e)

FIGURE 7: Typical curve of stress-time-AE energy evolution of coal-like material samples under different borehole arrangements. (a) Scheme I 03: complete samples. (b) Scheme II 02: samples with boreholes. (c) Scheme III 02: samples with borehole with stepwise increased borehole depth. (d) Scheme IV 01: samples with borehole with stepwise increased borehole diameter. (e) Scheme V 03: samples with borehole with stepwise increased borehole depth and borehole diameter. 
scheme II. However, the most noticeable effect of the energy hysteresis release is in scheme $\mathrm{V}$, and the energy released after the peak load reaches the total of $94.18 \%$. It can be seen that the existence of the borehole structure causes the internal energy release in the coal-like material sample to lag, reducing the sudden increment in the amount of energy released by the coal before the peak value, thereby reducing the damage evolution degree before the peak load of the sample and improving the stability of the coal-like material sample. The diameter and the depth of the borehole both increase stepwise, which can postpone the release of internal energy of the coal-like material sample to the utmost extent.

4.2. Analysis of Influence of Drilling Arrangement on $A E$ Spectrum Characteristics of Coal-like Material Sample. The acoustic emission signal can reflect different information in the time domain and the frequency domain, respectively. For this reason, this paper performs fast Fourier transform (FFT) on the acoustic emission signal and discusses the influence of borehole arrangement form on the acoustic emission characteristics of coal-like material sample from the acoustic emission frequency domain. In the spectrogram, the frequency corresponding to the maximum amplitude is defined as the peak frequency, and the frequency corresponding to the second largest amplitude is defined as the subdominant frequency $[26,27]$. This paper selects the acoustic emission electrical signal at the critical point of elastic deformation and plastic deformation during the sample loading process, because the sample has just undergone elastic deformation stage at this point, and the internal elastic energy conversion rate is largest. Plastic deformation has not yet been carried out at this point, and there is no internal fracture signal interference, which can well reflect the characteristics of the acoustic emission spectrum of the sample during energy accumulation.

Figure 8 shows the acoustic emission spectrum of the coallike material sample during the different borehole arrangements. The figure shows that the main frequency of the sample's acoustic emission is basically the same under different borehole arrangement forms. The main frequency is maintained at around $151 \mathrm{kHz}$, which indicates that the hole structure has little effect on the magnitude of the main frequency of the acoustic emission signal during the loading of coal-like material sample. Observing the width of the main frequency, we can find that the existence of the hole structure also has little effect on the abundance of the main frequency of acoustic emission during the loading of coal-like material sample. It can be seen that the peak frequency and richness of the acoustic emission signal during the loading process of coal-like material sample belong to the inherent nature of sample and do not change with the change in its strength and structure. Although the hole structure has little effect on the peak frequency, the influence of the hole structure on the subdominant frequency is quite obvious. As the volume of the hole structure increases, the richness of the subdominant frequency also increases. It can be seen that the existence of the hole structure significantly increases the width of the subdominant frequency of the acoustic emission signal.

The FFT transformation divides the signal band into equal linear intervals and can roughly recognize the difference in signal frequency characteristics of different broken structures. To further analyze the relationship between the signal frequency band energy and the hole structure and to find the frequency band energy, especially the variation between the main frequency band energy and the hole structure, a more elaborate wavelet packet transformation method is needed.

\section{Acoustic Emission Signal Wavelet Packet Transform and Frequency Band Energy Feature Analysis}

Wavelet Packet Analysis (WPA) method is more precise than wavelet analysis. It can accurately analyze both low and high frequencies simultaneously, without causing any loss or overlapping in the signal. For a given orthogonal wavelet function, a set of wavelet packet bases can be generated. Each wavelet packet base provides a specific signal analysis method, which can decompose the signal into different frequency range components and save the signal energy. It can also accurately reconstruct the signal according to the characteristic coefficients of each component $[28,29]$. Selecting different wavelet bases to analyze the same signal will also produce different results, so wavelet basis selection is of great importance. Based on the characteristics of acoustic emission signals, the functions of the available wavelet should have better time-domain compactness, smoothness, and symmetry. Based on previous studies, we chose the Daubechies wavelet family [30]. The db wavelet has a different sequence $(\mathrm{dbN})$ according to the vanishing moment $\mathrm{N}$. This paper selected the most commonly used db3 wavelet.

From the FFT-converted spectrogram, it can be found that the peak frequencies of the acoustic emission of coallike material samples under different borehole arrangements are concentrated at about $151 \mathrm{kHz}$. For this reason, this paper performs wavelet packet change on the above acoustic emission signals to investigate the effect of hole defects on the band energy of the acoustic emission signals. Since the sampling frequency of the acoustic emission in the test is $750 \mathrm{kHz}$ and the Nyquist frequency is $375 \mathrm{kHz}$, the signal can be decomposed into three layers. The bandwidth of the third layer is $46.875 \mathrm{kHz}$, and the decomposed spectrum is according to the Gray code sorting. To make the spectral energy relationship more intuitive, the spectral distribution and the decomposition sequence number of the decomposition are now rearranged as shown in Table 3.

5.1. AE Waveform Signal Wavelet Packet Decomposition Energy Calculation of Each Frequency Band. Decomposing the acoustic emission signal into the third layer produces $2^{3}$ component signals. Let the energy corresponding to one of the component signals $S_{3 j}$ be $E_{3 j}$; then, 


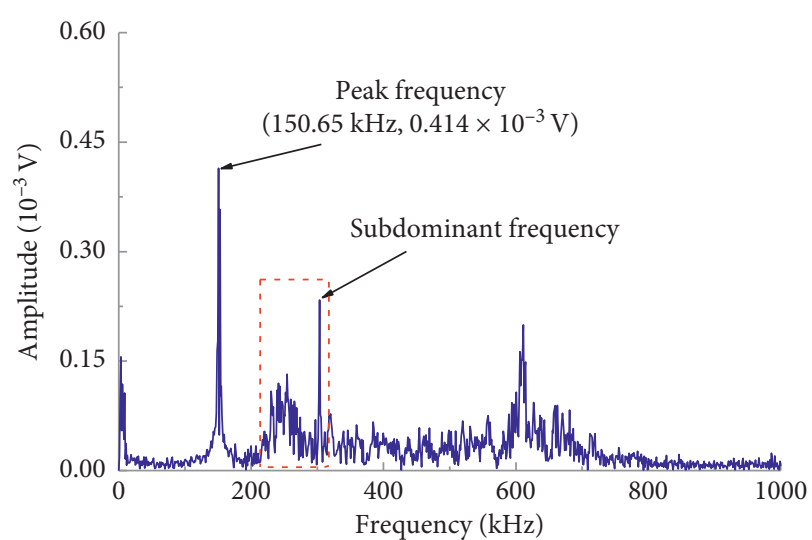

(a)

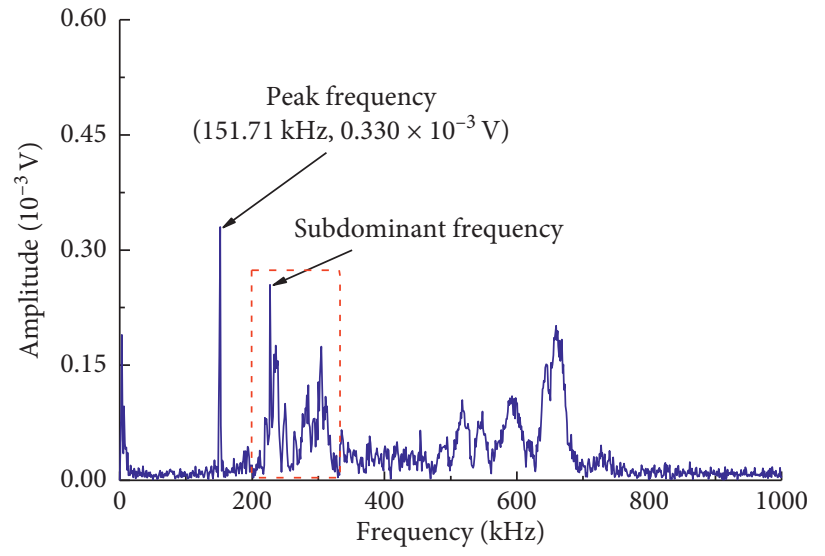

(c)

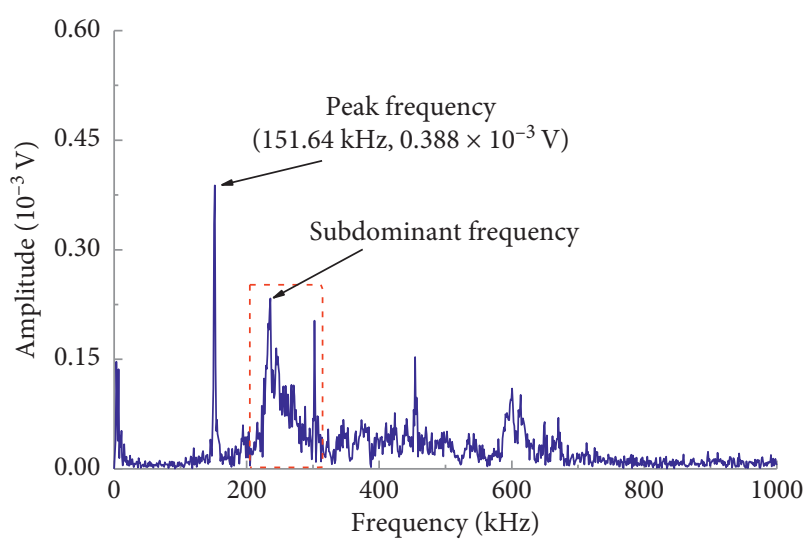

(b)

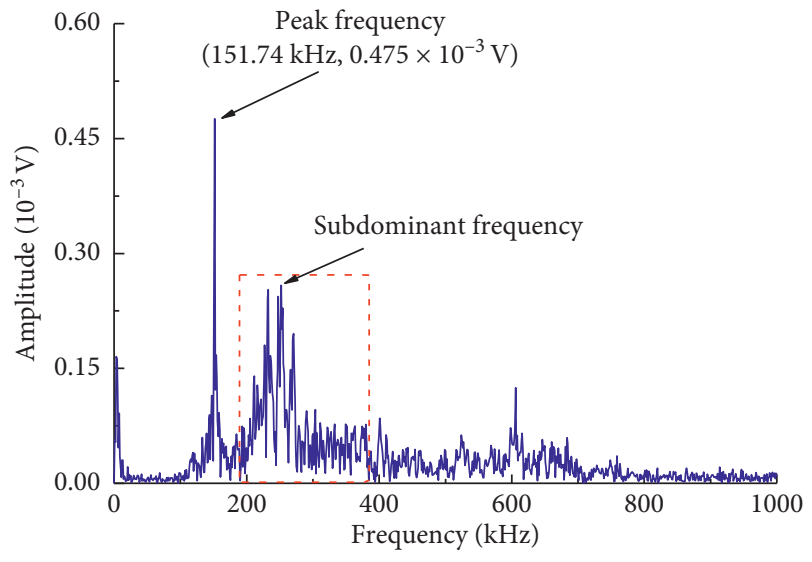

(d)

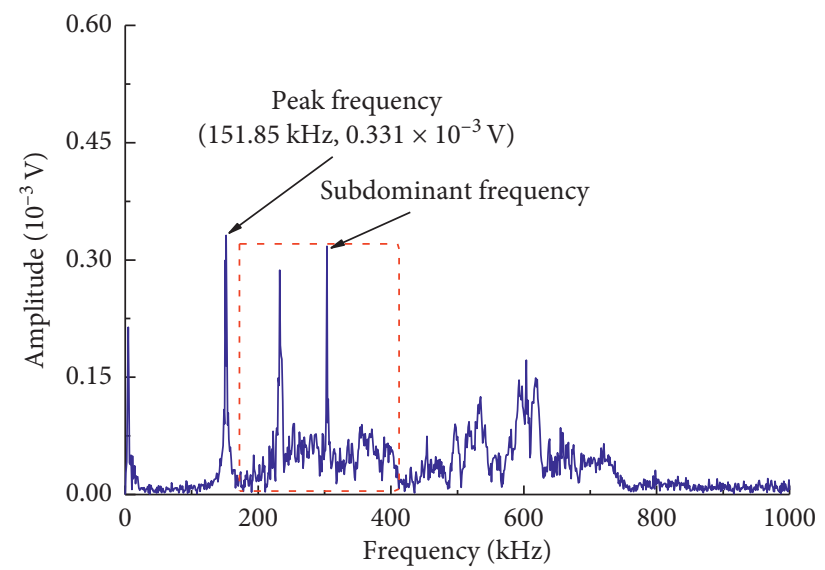

(e)

FIgURE 8: Amplitude and frequency characteristics of coal-like material samples under different borehole arrangements. (a) Scheme I 03: complete samples. (b) Scheme II 02: samples with boreholes. (c) Scheme III 02: samples with borehole with stepwise increased borehole depth. (d) Scheme IV 01: samples with borehole with stepwise increased borehole diameter. (e) Scheme V 03: samples with borehole with stepwise increased borehole depth and borehole diameter.

$$
E_{3 j}=\left|\int S_{3 j}\right|^{2} \mathrm{~d} t=\sum_{k=1}^{m}\left|x_{j k}\right|^{2},
$$

Obviously, the sum of the energies of the eight component signals is the total energy of the signal being decomposed:

where $x_{j k}(j=1,2, \ldots, 23 ; k=1,2,3, \ldots, m$, where $m$ is the number of discrete sampling points of the signal) is the discrete point amplitude of the reconstructed signal $S_{3 j}$. 
TABLE 3: Wavelet packet component reconstruction signal spectrum range.

\begin{tabular}{lcc}
\hline The serial number of components & Wavelet packet component & Frequency range $(\mathrm{kHz})$ \\
\hline 1 & $(3,0)$ & $0 \sim 46.875$ \\
2 & $(3,1)$ & $46.875 \sim 93.75$ \\
3 & $(3,3)$ & $93.75 \sim 140.625$ \\
4 & $(3,2)$ & $140.625 \sim 187.5$ \\
5 & $(3,6)$ & $187.5 \sim 234.375$ \\
6 & $(3,7)$ & $234.375 \sim 281.25$ \\
7 & $(3,5)$ & $281.25 \sim 328.125$ \\
8 & $(3,4)$ & $328.125 \sim 375$ \\
\hline
\end{tabular}

$$
E_{0}=\sum_{j=1}^{2^{3}} E_{3 j}
$$

Combining equations (7) and (8) and using MATLAB to calculate the energy percentage of each frequency band component, the energy distribution of each frequency band of acoustic emission signals during the loading of the coallike material sample can be obtained under different borehole arrangement forms.

\subsection{AE Signal Frequency Band Energy Analysis of Coal-like} Material Sample under Different Borehole Arrangements. Figure 9 is a histogram of the frequency band energy percentage calculated and drawn using Matlab. The component numbers have been arranged in the order of the spectrum from low to high. The original acoustic emission signal data in each histogram is consistent with Figure 8. In the figure, component No. 4 is the frequency band of the main frequency. By comparing and analyzing the frequency band energy in the complete sample (Scheme I) and the holecontaining sample (Scheme II), it can be seen that the existence of the hole defect reduces the main frequency energy and increases the frequency band's energy in No. 7, while the frequency energy of the remaining component bands does not change much. This is because the existence of the hole defect causes the release of energy into the hole during the loading of the sample to reduce the development of the internal microcracks and the release of low-frequency elastic wave. The energy of the main frequency is reduced at the same time and the existence of the pore space has a certain guiding effect on the development of the main crack in the sample, which increases the release of the high-frequency elastic wave, thereby increasing the energy of the highfrequency band. Schemes III, IV, and V are based on Scheme II to increase the diameter and the depth of the hole at the same time. By observing the histogram of the frequency band energy distribution in the above three schemes, it can be seen that the main-frequency energy decreases significantly when the hole diameter increases stepwise, but the energy in the high-frequency band does not increase significantly. When the depth of the hole increases stepwise, the main-frequency's energy decreases, and the high-frequency energy is basically unchanged; when the diameter and the depth of the hole are increased stepwise, the energy of the main-frequency band is minimized. The energy of the high- frequency band is also reduced compared with Schemes III and IV. It can be explained that the arrangement of the hole defects in Scheme $\mathrm{V}$ can reduce the development of microscopic and macroscopic cracks and better maintain the stability of the coal-like material sample.

\section{Discussion}

During the loading of the complete sample in Section 3.1, the $\mathrm{AE}$ energy released was evenly distributed throughout the loading process. However, the AE energy during the loading process of the sample with holes defects was mainly concentrated after the peak load. The main reason is that the existence of hole defects has a certain dissipation effect on the internal energy of coal samples during the early loading stage. The main manifestation of this part of the energy dissipation is spalling of the borehole wall $[31,32]$. In the early stage of loading, the main means of energy dissipation in the complete sample is through the development and expansion of cracks. Many small cracks are formed inside the sample. The formation of these cracks will release elastic waves to the outside, so the AE energy before the peak load of the complete sample releases more samples with hole defects [33]. Secondly, the existence of the hole defects has a certain guiding effect on the internal energy of the sample. The energy input by the press will be evenly distributed around the borehole. At the same time, the circular structure has a certain stability and will reduce part of the crack's growth. During the loading of the complete sample, stress concentration will be formed in a large area of crack propagation. This stress will continue to be used for the development of cracks, so that the phenomenon of $\mathrm{AE}$ energy released is greater than that in the sample with holes before the peak load is formed. In the postpeak stage, due to the relatively small internal crack growth in the samples with hole defects, a sudden collapse occurred when the maximum load is exceeded leading to the release of a large amount of AE energy. In Section 4.1, the main frequency of the acoustic emission signal remained basically unchanged under different drilling structures. The main reason is that the drilling structure has little effect on the overall stress change in the sample. However, the dominant frequency of the acoustic emission signal during the loading of the coal and rock masses has the property that it does not change with the change in the stress of the sample. Therefore, the dominant frequency of the acoustic emission signal remains basically unchanged under different drilling structures during the test. The existence of 


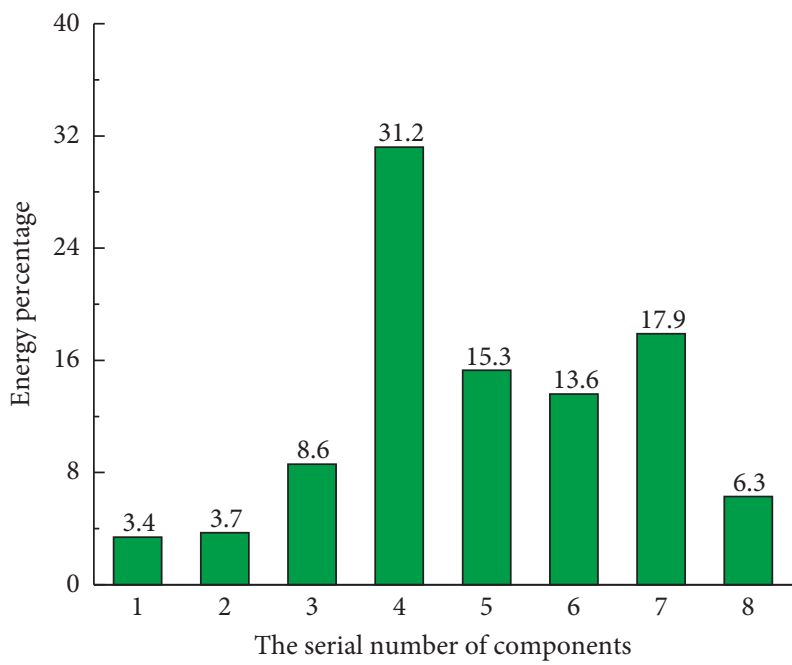

(a)

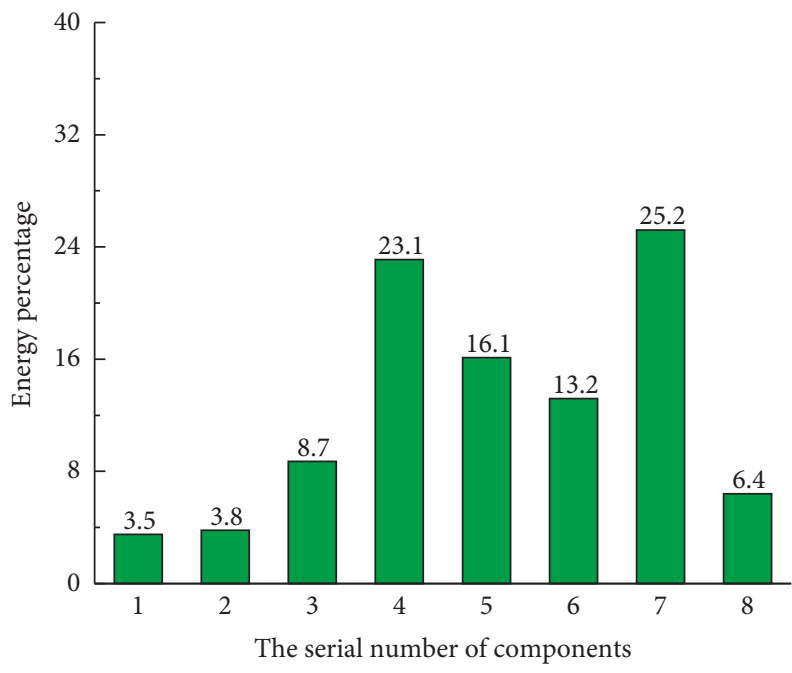

(c)

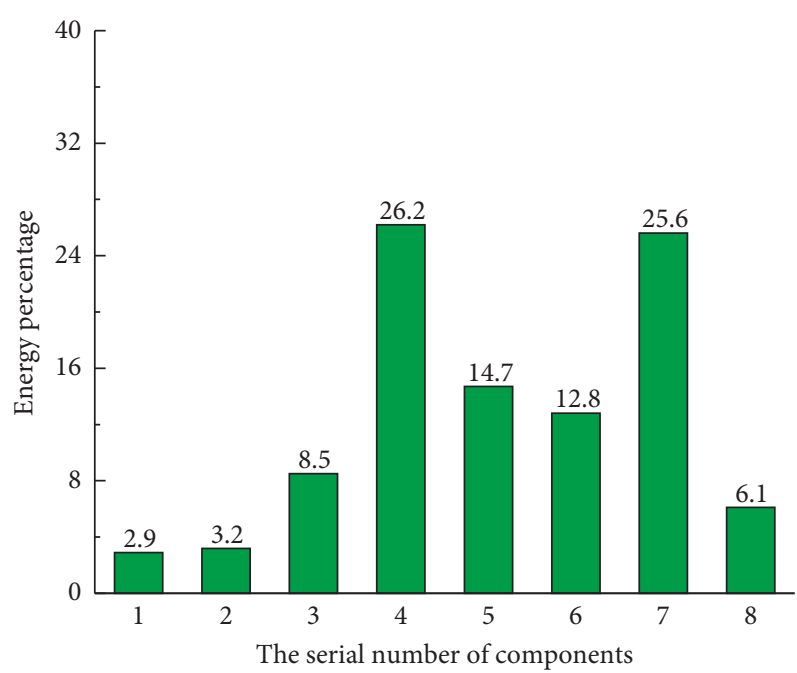

(b)

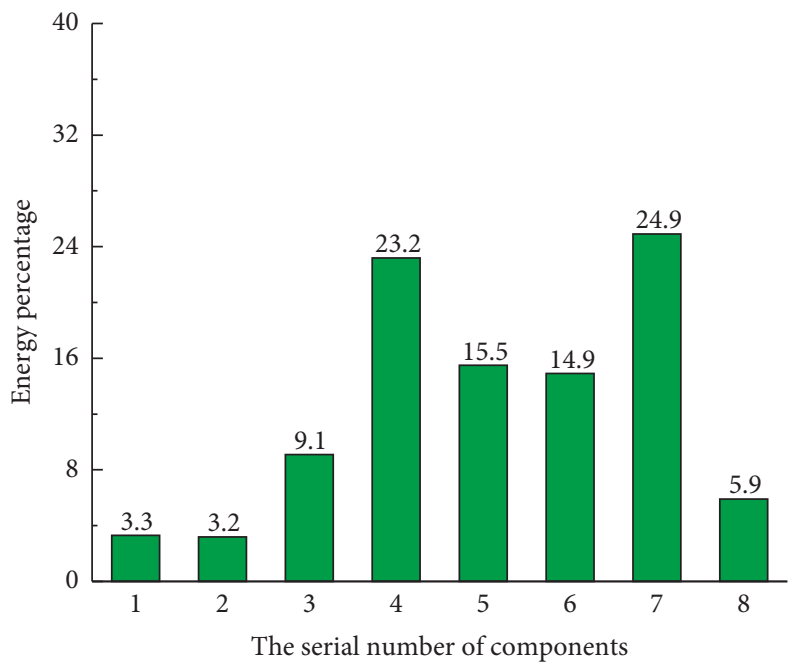

(d)

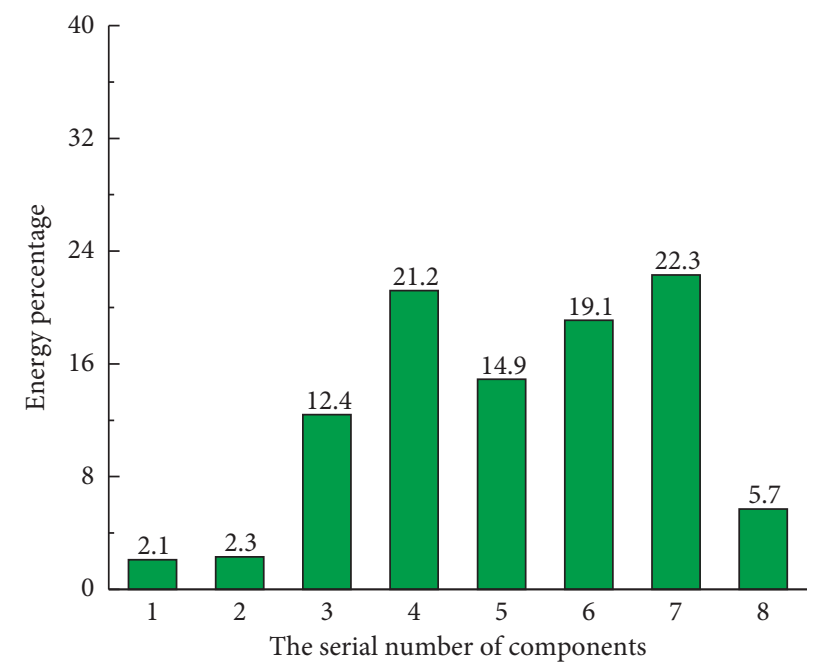

(e)

FIGURE 9: Frequency band energy histogram of acoustic emission signals of coal-like material samples under different borehole arrangements. (a) Scheme I 03: complete samples. (b) Scheme II 02: samples with boreholes. (c) Scheme III 02: samples with borehole with stepwise increased borehole depth. (d) Scheme IV 01: samples with borehole with stepwise increased borehole diameter. (e) Scheme V 03: samples with borehole with stepwise increased borehole depth and borehole diameter. 
the drilling structure in Section 4.2 significantly reduces the energy of the main-frequency band. The main reason is that the existence of hole defects reduces the development of microcracks during the loading of the sample and these microcracks are often released outward in the form of lowfrequency elastic waves. Therefore, the phenomenon of lowfrequency energy in the main frequency is reduced.

From the analysis of energy transformation, elastic strain energy growth, and the acoustic characteristics of coal-like material samples with different drilling arrangements, it can be seen that when the diameter and the depth of boreholes are increased stepwise, the energy dissipation of the samples can be increased to the maximum limit, and the energy released is delayed. This leads to a reduction in the $e$ storage of elastic energy and the degree of fracture development. Therefore, the best pressure relief effect can be achieved when the borehole diameter and the depth are increased stepwise.

\section{Conclusion}

Using prefabricated complete samples, samples with boreholes, and samples with borehole with stepwise increased depth and diameter, respectively, this study utilized these coal-like material samples using SH-II type acoustic emission system which performs characteristic parameter monitoring. From the findings of the study, we have the following conclusions:

(1) The existence of borehole defects can significantly reduce the conversion ratio and growth rate of elastic energy during the loading of the coal-like material sample, and the conversion ratio and growth rate of the elastic energy are further reduced when the diameter and the depth of the hole defects are stepwise increased to the lowest point.

(2) During the loading process of the coal-like material samples with borehole defects, the AE jump point occurs more frequently after the peak when compared to the complete sample, and the overall energy value of the jump point after the peak load is higher than that before the peak load. The existence of the hole defects lags behind the release of the internal energy of coal-like material sample, reducing the degree of damage inside the sample before the peak load, and, by stepwise increasing the diameter and the depth of borehole, the release of internal energy attains its maximum limit.

(3) The arrangement of boreholes has little effect on the size and richness of the main frequency of acoustic emission during the loading of the coal-like material sample, but the influence of hole defects on the secondary frequency of acoustic emission during the loading of the sample was obvious. Increment in the volume of hole defects results in an increase in both the primary and the secondary frequencies.

(4) The arrangement of the borehole defects can significantly reduce the main-frequency energy of the acoustic emission signal of the coal-like material sample. When the diameter and the depth of the holes are arranged stepwise at the same time, the energy of the main-frequency band reduces significantly to its minimum level, leading to a reduction in the development of microcracks and macrocracks.

\section{Data Availability}

The data used to support the findings of this study are available from the corresponding author upon request.

\section{Conflicts of Interest}

The authors declare that there are no conflicts of interest regarding the publication of this paper.

\section{Acknowledgments}

This research was supported by the National Natural Science Foundation of China (Grant nos. 51674107, 51774121, and 51574115), Postdoctoral Science Research Program of Heilongjiang Province of China (Grant no. LBH-Q18111), Natural Science Foundation of Heilongjiang Province (Grant no. LH2019E087), and the Fundamental Research Funds for the Provincial Universities of Heilongjiang Province of China in 2018 (Grant no. 2018-KYYWF-1181). The authors would like to thank all members in Heilongjiang Ground Pressure and Gas Control in Deep Mining Key Lab (GPGC) for their help with the fieldwork.

\section{References}

[1] W. P. Huang, Q. Yuan, Y. L. Tan et al., “An innovative support technology employing a concrete-filled steel tubular structure for a 1000-m-deep roadway in a high in situ stress field," Tunnelling and Underground Space Technology, vol. 73, pp. 26-36, 2018.

[2] C.-P. Lu, G.-J. Liu, Y. Liu, N. Zhang, J.-H. Xue, and L. Zhang, "Microseismic multi-parameter characteristics of rockburst hazard induced by hard roof fall and high stress concentration," International Journal of Rock Mechanics and Mining Sciences, vol. 76, pp. 18-32, 2015.

[3] Y. L. Tan, W. Y. Guo, H. Q. Xin et al., "Key technology of rock burst monitoring and control in deep coal mining," Journal of China Coal Society, vol. 44, no. 1, pp. 160-172, 2019.

[4] P. Konicek, K. Soucek, L. Stas, and R. Singh, "Long-hole destress blasting for rockburst control during deep underground coal mining," International Journal of Rock Mechanics and Mining Sciences, vol. 61, pp. 141-153, 2013.

[5] X. F. Liu, G. Xu, C. Zhang et al., "Time effect of water injection on the mechanical properties of coal and its application in rockburst prevention in mining," Energies, vol. 10, no. 11, pp. 1-26, 2017.

[6] Y. L. Wen, G. J. Zhang, Z. Q. Zhang et al., "Numerical experiments of drilling pressure relief preventing roadway rock burst," Applied Mechanics and Materials, vol. 353-356, pp. 1583-1587, 2013.

[7] Q.-h. Zhu, W.-b. Lu, J.-s. Sun, Y. Luo, and M. Chen, "Prevention of rockburst by guide holes based on numerical simulations," Mining Science and Technology (China), vol. 19, no. 3, pp. 346-351, 2009. 
[8] H. G. Liu, Y. N. He, J. H. Xu et al., "Numerical simulation and industrial test of boreholes destressing technology in deep coal tunnel," Journal of China Coal Society, vol. 32, no. 1, pp. 33-37, 2007.

[9] Y. Y. Li, S. C. Zhang, L. Q. Gao et al., "Mechanism and prevention of pressure burst in step region based on overburden strata movement of unequal length working face," Rock and Soil Mechanics, vol. 37, no. 11, pp. 3283-3290, 2016.

[10] H. Zhao, T. Wang, H. Zhang, and Z. Wei, "Comparison of local load influence on crack evolution of coal and briquette coal samples," Advances in Civil Engineering, vol. 2018, Article ID 3817397, 12 pages, 2018.

[11] J. K. Li, Z. H. Xiong, D. S. Liu et al., "Numeric simulation of bore hole pressure relief preventing roadway rockburst of a mine," Journal of Xi'an University of Science and Technology, vol. 29, no. 4, pp. 424-426, 2009.

[12] B. Huang, W. Y. Guo, Z. Y. Fu et al., "Experimental investigation of the influence of drilling arrangements on the mechanical behavior of rock models," Geotechnical and Geological Engineering, vol. 36, no. 4, pp. 2425-2436, 2018.

[13] C. Y. Jia, Y. J. Jiang, X. P. Zhang et al., "Laboratory and numerical experiments on pressure relief mechanism of largediameter boreholes," Chinese Journal of Geotechnical Engineering, vol. 39, no. 6, pp. 1115-1122, 2017.

[14] S. T. Zhu, F. X. Jiang, X. F. Shi et al., "Energy dissipation index method for determining rockburst prevention drilling parameters," Rock and Soil Mechanics, vol. 36, no. 8, pp. 2270-2276, 2015.

[15] X. Hu, G. Su, G. Chen et al., "Experiment on rockburst process of borehole and its acoustic emission characteristics," Rock Mechanics and Rock Engineering, vol. 52, no. 3, pp. 783-802, 2019.

[16] Z. Chen, G. Su, J. W. Ju, and J. Jiang, "Experimental study on energy dissipation of fragments during rockburst," Bulletin of Engineering Geology and the Environment, vol. 78, no. 7, pp. 5369-5386, 2019.

[17] X. Sun, H. Xu, L. Zheng, M. He, and W. Gong, "An experimental investigation on acoustic emission characteristics of sandstone rockburst with different moisture contents," Science China Technological Sciences, vol. 59, no. 10, pp. 15491558, 2016.

[18] Z. Liu, A. Cao, G. Liu, and J. Li, "Experimental research on stress relief of high-stress coal based on noncoupling blasting," Arabian Journal for Science and Engineering, vol. 43, no. 7, pp. 3717-3724, 2018.

[19] J. H. Liu, F. X. Jiang, G. J. Sun et al., "Mechanism of intensive venting pulverized coal to prevent coal burst and its application," Chinese Journal of Rock Mechanics and Engineering, vol. 33, no. 4, pp. 747-754, 2014.

[20] H. P. Xie, Y. Ju, and L. Y. Li, "Criteria for strength and structural failure of rocks based on energy dissipation and energy release principles," Chinese Journal of Rock Mechanics and Engineering, vol. 24, no. 17, pp. 3003-3010, 2005.

[21] G. LIU, F. K. Xiao, and T. Qin, "Rock mechanics characteristics and acoustic emission rule under small-size effect," Chinese Journal of Rock Mechanics and Engineering, vol. 24, no. S2, pp. 3905-3917, 2018.

[22] K. Peng, Z. Liu, Q. Zou, Q. Wu, and J. Zhou, "Mechanical property of granite from different buried depths under uniaxial compression and dynamic impact: an energy-based investigation," Powder Technology, vol. 362, pp. 729-744, 2020.

[23] H. Deng, S. Yu, J. Deng, B. Ke, and F. Bin, "Experimental investigation on energy mechanism of freezing-thawing treated sandstone under uniaxial static compression," KSCE Journal of Civil Engineering, vol. 23, no. 5, pp. 2074-2082, 2019.

[24] D. M. Zhang, X. Bai, G. Z. Yin et al., "Analysis of acoustic emission parameters and energy dissipation characteristics and damage evolution of bedding rock failure process under uniaxial compression," Journal of China Coal Society, vol. 43, no. 3, pp. 646-656, 2018.

[25] D. Huang, Q. Tan, and R. Q. Huang, "Mechanism of strain energy conversion process for marble damage and fracture under high stress and rapid unloading," Chinese Journal of Rock Mechanics and Engineering, vol. 31, no. 12, pp. 24832493, 2012.

[26] Y. B. Zhang, P. Liang, L. Sun et al., "Spectral characteristics of $\mathrm{AE}$ in the process of saturated granite fracture under uniaxial compression," Rock and Soil Mechanics, vol. 40, no. 1, pp. 2497-2506, 2019.

[27] Y. X. Ban, X. Fu, Q. Xie et al., "Evaluation of fracture morphology of shale in Brazilian tests and analysis of power spectral characteristics," Chinese Journal of Geotechnical Engineering, vol. 41, no. 12, pp. 2307-2315, 2019.

[28] X. D. Zhang and Z. Bao, Nonstationary Signal Analysis and Processing, National Defense Industry Press, Beijing, China, 1998.

[29] Y. S. Lai, Y. Xiong, and L. F. Cheng, "Frequency band energy characteristics of acoustic emission signals in damage process of concrete under uniaxial compression," Journal of Vibration and Shock, vol. 33, no. 10, pp. 177-182, 2014.

[30] T. H. Ling, Y. C. Liao, and S. Zhang, “Application of wavelet packet method in frequency band energy distribution of rock acoustic emission signals under impact loading," Journal of Vibration and Shock, vol. 29, no. 10, pp. 127-130, 2010.

[31] Z. H. Shangguan, Z. W. Zhu, and W. R. Tang, "Dynamic impact experiment and numerical simulation of frozen soil with prefabricated holes," Journal of Engineering Mechanics, vol. 146 , no. 8, 2020.

[32] N. Wu, Z. Z. Liang, J. R. Zhou et al., "Energy evolution characteristics of coal specimens with preformed holes under uniaxial compression," Geomechanics and Engineering, vol. 21, no. 1, pp. 55-66, 2020.

[33] B. Fu, L. H. Hu, and C. A. Tang, "Experimental and numerical investigations on crack development and mechanical behavior of marble under uniaxial cyclic loading compression," International Journal of Rock Mechanics and Mining Sciences, vol. 130, 2020. 